\title{
Disabilities and Dangerous Digital Footprints: The Need for Light-Touch Guidance
}

\author{
Ian Freckelton QC* \\ Barrister, Crockett Chambers, Australia \\ Professor of Law and Psychiatry, University of Melbourne, Australia \\ Adjunct Professor of Forensic Medicine, Monash University, Australia \\ Adjunct Professor, Johns Hopkins University, United States
}

Submission: January 31, 2020; Published: February 20, 2020

*Corresponding author: Ian Freckelton QC, Professor, c/o Foley's List, Owen Dixon Chambers, 205 William St, Melbourne, 3000, Victoria, Australia

\begin{abstract}
Persons with intellectual and developmental disorders have the potential to derive considerable benefits from uptake of online environments. However, by reason of what may be their lack of discernment, their propensity to obsessionality and their digital naivete, they are at risk of both being victimised and engaging in unlawful forms of behaviour. This article identifies a number of scenarios in which such persons have been found by courts to have engaged in problematic conduct arising from their disorders and highlights the particular risks of online criminal offending. It calls for upskilling of persons with intellectual and developmental disabilities so that they are better equipped to navigate the Internet without such risks. It also argues for online-aware professionals to develop light-touch forms of guidance to assist prudent and safe Internet usage for those with intellectual and developmental disabilities.

Keywords: Digital footprints; Vulnerabilities; Online environment; Internet; Attention Deficit Hyperactivity Disorder (ADHD) ; Foetal Alcohol Spectrum Disorder (FASD); Autism spectrum disorder; Obsessive Compulsive Disorder (OCD); Intellectual and developmental disabilities
\end{abstract}

\section{Introduction}

The online environment is ubiquitous. It is accessed more and more often by most categories of persons within our community. Increasingly, we are all, and are perceived to be, what we view online. Our interactions with search engines such as Google tell much about us, including about our anxieties, pathologies and fantasies. Our digital footprint identifies our interests, our absorptions, our purchasing behaviour, our reading habits, our musical preferences, our gaming likes, and much more. This raises a range of privacy and security issues. To a degree, those of us who are alert to the potential for external monitoring of our conduct and to the ethics and perils of the Internet take steps to minimise sinister oversight by careful orchestration of privacy settings and management of cookies.

However, for even with those who are 'computerate', the Internet has many dark and difficult aspects. Its challenges are exacerbated for those who are not so proficient with online skills and those who have disabilities that limit their ability to be discerning and prudent in their online behaviour. Some of these challenges have legal ramifications. In 2006 Thoreau [1] argued that "the reality of the Internet may not be as emancipatory for disabled people as has been claimed." The passage of time has vindicated his concerns. Limited digital sophistication, naivete, credulity, the existence of obsessions, and impediments to selfregulation create the risk of ongoing behaviour which can be both antisocial and such as to render a person vulnerable to exploitation in the online environment.

In addition, those with intellectual disabilities and with conditions such as Autism Spectrum Disorder, Attention Deficit Hyperactivity Disorder (ADHD), Foetal Alcohol Spectrum Disorder (FASD), Tourette's Disorder, Obsessive Compulsive Disorder (OCD), depressive, anxiety and personality disorders, many of which frequently co-exist, may well behave impulsively and in a particularly patterned way without heed for the extent to which their conduct can be monitored. This can render them vulnerable to criminal prosecution for conduct such as viewing and/or collecting illegal material, such as child pornography; cyber-bullying; stalking; and hacking, but it can also render such persons vulnerable to opportunistic commercial, sexual and other predation. This paper identifies the online risks for persons with intellectual and developmental disabilities and reflects on what needs to be done to reduce them. 


\section{Global Journal of Intellectual \& Developmental Disabilities}

Intellectual and Developmental Disabilities and the Internet

The online environment offers many benefits to those with intellectual and developmental disabilities [2]. These include learning, social interaction and participation in mutual support groups $[3,4]$. In particular, online usage has the potential to disrupt the malign effects of loneliness, isolation and boredom that can be particularly stigmatising and disabling for persons with intellectual and developmental disabilities [5]. It can provide a forum for positive social and emotional experiences in friendships, development of social identity and self-esteem, as well as hobbies, learning opportunities and enjoyment [6]. Social capital can be leveraged [7] and new interests developed and pursued. A 2016 systematic review and thematic analysis, for instance, found that the benefits of access to information and communication technologies by persons with intellectual disabilities include increased opportunities for education, creativity, learning, communication, and civic engagement [8].

However, there are also well-recognised online risks for those with intellectual and developmental disabilities [9-13] such as unwanted contact, being the victim of grooming, sexual harassment, cyberbullying and attempts at financial and other exploitation [10]. Many of the risks that arise are enabled by a tendency to invest trust and believe what is read online and a lack of capacity for critical discernment that can contribute to vulnerability [10-12]. Persons with such disabilities may also have limited capacity for exercise of insight and judgment [11], when others would regard themselves on notice of warning signs and behaviours online. This can be particularly pronounced with young persons $[14,15]$.

\section{Risks of Criminal Offending}

We know something about the categories of criminal infraction in which persons with a number of forms of intellectual and developmental disorders engage. For instance, persons with Asperger's Disorder/Autism Spectrum Disorder disproportionately commit stalking offences, online crimes such as hacking and harassment, arson and other fire-lighting behaviours, offences of spontaneous or reactive violence, and sexual offending arising from poor social skills and insensitivity to cues [16,17]. A number of the same offending profiles exist for persons with ADHD [18], Tourette's Disorder [19] and Obsessive Compulsive Disorder (OCD) [20], arising from a combination of social isolation, limited communication skills, impulsivity, obsessionality and limitations of memory. Some of the same issues arise for persons with intellectual and developmental disorders, generally, as well as those with Foetal Alcohol Spectrum Disorder, [21-25] especially when these are co-morbid with other conditions, as they often are. Such persons may also be highly suggestible and take few or no measures to cover up their conduct, resulting in a digital footprint, for instance, that makes their unlawful behaviour easy to identify, investigate and prosecute, although they are subject to elevated risks of miscarriages of justice. There is thus a real vulnerability of such persons to engaging in problematic behaviours, to being identified as such, and to being exploited and criminally investigated, interviewed [23] and prosecuted in disproportionate numbers.

A small number of examples highlights the issues of both vulnerability and co-morbidity. The appropriateness of persons with Asperger's Disorder, now termed Autism Spectrum Disorder to be extradited from one jurisdiction to another to face computer offending charges is illustrative and has been contentious. Ultimately the extradition of Gary McKinnon from England to the United States for serious hacking offences against the United States military was halted by the Home Secretary after a series of legal challenges failed. McKinnon suffered from a combination of Asperger's Disorder and depression. The then Home Secretary, Theresa May, stated that: "He has Asperger's syndrome, and suffers from depressive illness. The legal question before me is now whether the extent of that illness is sufficient to preclude extradition. After careful consideration of all of the relevant material, I have concluded that Mr McKinnon's extradition would give rise to such a high risk of him ending his life that a decision to extradite would be incompatible with Mr McKinnon's human rights" [26].

Another extradition case which achieved international notoriety was that involving Lauri Love who was charged with masterminding a 2013 cyber-attack by Anonymous on United States government websites [27-29]. Love was found to suffer from Asperger's Disorder which was asserted by an expert witness in his case, Professor Baron-Cohen, to be "a very serious disability because it causes him to become so absorbed in his interests that he neglects important areas of his life, such as his studies, and even his health" [27]. He also suffered from stress-related eczema and depression. Ultimately, Burnett LCJ and Ouseley J concluded that it would be oppressive to extradite Mr Love by reason of the combination of his physical and mental conditions. They found him to be at significant risk of suicide if extradited and observed that: "Were Mr Love not to be in segregation, his Asperger Syndrome and physical conditions would make him very vulnerable. He would be a likely target for bullying and intimidation by other prisoners. The response by the authorities would be segregation for his own protection, which would bring in all the problems of isolation to which we have already referred. He would have no support network available in prison in the United States. There is no basis upon which we could conclude that the severity of the problems would be brought swiftly to an end by early transfer to the United Kingdom" [27] at [120].

The decision of the New Zealand High Court in Glover v Police [30] illustrates the propensity of some persons with Asperger's Disorder to lose perspective as a result of the obsessions that they develop and from which they cannot readily extricate their ruminations. Mr Glover had damaged another man's property 
on a number of occasions, describing himself as a "road safety activist". He was of the view that a footpath needed to run past the front of his property but, to his consternation, the local council had licensed a neighbour to use a garden area as part of his front garden. Mr Glover advanced a technical legal argument at his trial that he had a claim of right or lawful justification to damage this area of the neighbour's property. He did not succeed. At first instance he was convicted and fined.

On appeal evidence was given of Mr Glover's Asperger's Disorder and it was argued that the imposition of a conviction would be likely to increase his sense of alienation, frustration and despair. Justice Clifford accepted the relevance of Mr Glover's condition to his conduct and concluded that his offending "must be regarded as significantly less than that of a healthy and rationally thinking person" [29] at [21]. He found Mr Glover's "strong interest" in road safety was a manifestation of his symptoms and concluded that Mr Glover had not been motivated by any form of criminal intent. He also determined that Asperger's Disorder went "a considerable way to explain his failure to express remorse or to offer to make amends, which appear to be the result of his rigidity of mind and egocentric perspective" at [29] Ultimately, he concluded that the imposition of a sentence of conviction would have a disproportionate and counter-therapeutic effect upon Mr Glover and, although Mr Glover lacked remorse and had not offered to make amends, again this was attributable to his condition. He discharged him without conviction and quashed the order for Mr Glover to perform community work.

Another case in which Asperger's Disorder was interpreted to reduce an accused person's culpability was Excell $v$ New Zealand Police [31], where a New Zealand High Court judge, on appeal, reduced the custodial sentence imposed on a person found with child pornography on his computer. The reason for the reduction was his having both Asperger's disorder and Kallmann Syndrome (a pathology of the hypothalamus). Justice Young accepted the expert evidence that Mr Excell had a lack of empathy for the victims, whom he seemed to think would be likely to be consenting to the sexual activity in the videos and other material, and the fact that he acknowledged in the right situation he would be likely to sexually offend against a child. However, Justice Young also found that Mr Excell's Asperger's Disorder had affected his capacity to develop special relationships, to perceive feelings in others, and had given him a tendency to fixate on certain subject matter. Justice Young accepted that the Mr Excell's disorder had contributed to his lack of understanding of appropriate sexual behaviour resulting in his social isolation and in turn contributing to his attachment to children. He also noted that the experience of prison would be considerably more onerous for him than for most other offenders.

In another New Zealand case, $R v$ Walker [32], the offender, Mr Walker, pleaded guilty to the commission of a series of computer fraud offences when he was aged between 16 and 18 .
He developed and used software that enabled him to control infected computers remotely and to form a robot network a "bot net". He installed his software on tens of thousands of computers, thereby disabling antivirus software. While his modus operandi had the potential to function as an effective vehicle for fraud, there was no evidence that he had used it for such a purpose. Mr Walker, who had been diagnosed with a mild form of autism since childhood, described his offending as having been motivated principally by curiosity and showed signs of remorse and preparedness to pay reparation. Justice Potter accepted that Mr Walker had a "diminished understanding in relation to the nature of his offending by reason of his autism and that he was unaware of the harm that his activities could cause". He took into account that Mr Walker had attracted offers employment from a number of large corporations outside New Zealand and that the New Zealand Police were interested in offering him employment. He formed the view that Mr Walker had a "potentially outstanding future" and discharged him without conviction.

A well-known case which highlights the suggestibility at interview of persons with a range of disorders, including Foetal Alcohol Spectrum Disorder (FASD), is the 2015 decision of the Privy Council in $R v$ Pora [33], [24] On appeal from the New Zealand Supreme Court extensive evidence was adduced about the fact that that Mr Pora suffered from FASD which rendered him prone to being highly suggestible when interviewed by figures of authority such as police officers and to confabulate what he thought they wished to hear. This led the Privy Council to conclude that his confessions to police about a murder gave rise to a miscarriage of justice.

In $R v$ Friend [34] the Court of Appeal of England and Wales heard a referral of a man with ADHD in relation to his conviction for murder. At the time of his trial for murder Mr Friend was 15 and did not give evidence. An important issue that rose was whether an adverse inference should be drawn from his failure to do so. On appeal fresh expert evidence was given about Mr Friend suffering from ADHD which affected his capacity to give attention and about his impulsivity, short-term verbal memory and anxiety. The Court of Appeal concluded that had such evidence been available at trial the trial judge would not have ruled in favour of drawing any adverse inference in relation to his failing to give evidence. This was part of a very important ruling about the potentially contaminating effect of ADHD for persons charged with criminal offences.

In $R v$ Balogh [35] the Court of Appeal of England and Wales heard an appeal against the leniency of a sentence imposed upon Mr Balogh who suffered from Tourette's Disorder, OCD, ADHD, anxiety and depression for a rape which he self-reported. He was obsessively and pathologically contrite for the sexual interaction that had occurred with his victim. The trial judge gave Balogh no credit for his plea of guilty but the Court of Appeal found this to be unduly harsh and concluded that imposition of 
a sentence of imprisonment would be likely to worsen his ADHD symptomatology, including his sense of guilt, and put at risk a successful outcome from his release from custody.

This diverse array of judgments from appellate courts illustrates a number of the characteristics of persons with intellectual and developmental disorders. Many such persons suffer from more than one disorder. They are at enhanced risk of ill-considered actions, of poor exercise of judgment, of obsessionality and preoccupation, of impulsivity, of suggestibility when questioned, and of naivete in face of accusations of offending.

In an online environment there is the danger that these characteristics / symptoms will render such persons at particular risk of both offending and being dealt with harshly by the investigative processes of police and the imposition of sentences by courts. In particular, there is a danger that they will become problematically and uncritically focussed upon what they encounter in what they experience as the unthreatening and beguiling environment of the Internet and be unable to exercise sufficient discernment and critical judgment about what they see, what they read, and what they do online

\section{Risks for the Online Environment}

What should follow from recognition of the risks described in this paper is the deployment of particular efforts to work with persons with intellectual and developmental disabilities to educate and assist them to manage their online conduct by constructing and maintaining a healthy online environment [37] and to optimise digital inclusiveness [38], namely the learning, entertainment and relational opportunities that can flow from prudent and facilitated online access [39]. Such interventions need to be integrated by all who live with, work with and provide support to those with intellectual and developmental disabilities $[40,41]$.

As Molin, Sorbring and Löfgren-Mårtenson, [3] p.24 have observed: "These new virtual spaces create both opportunities and risks for users, especially when it comes to developing alternative identities that are not linked to common experiences of stigmatization and alienation". However, users cannot do it alone; they need assistance from professionals, many of whom are still finding their way themselves in the online environment. The risks adverted to by Molin, Sorbring and Löfgren-Mårtenson need to be mediated, on an individual basis, depending on the nature and degree of the person's disability, and thus their vulnerabilities, so as to minimise so far as possible the intrusiveness of monitoring and intervention and to maximise the potential for the exercise of autonomy by positive risk-taking approaches [42], as well as working toward safety for the individual.

While it has become orthodox to expend significant effort to upskill persons with intellectual and developmental disabilities with prosocial techniques, and latterly as a human right to promote equality of opportunity for internet access $[43,44]$, support also needs to be extended to online conduct so as to enhance the capacity to draw constructively on digital options and resources but also to reduce the potential for inappropriate behaviours which may lead to adverse consequences for persons with disabilities [45] and also for individuals who otherwise may become their direct and indirect victims. Chiner, Gomez-Puerat and Cardona-Molto [41] are correct to identify that: "Providing them with the rightstrategies to identify, prevent and cope with the potential risks of the Internet will lead to a better understanding of the benefits of this technology and, therefore, to the ability to promote the responsible use of the Internet by people with ID."

However, it is time to move to the next phase of these analyses. The challenge that is emerging is for suitably skilled and online-aware professionals to develop practical strategies and methodologies for light-touch provision of guidance and assistance with online behaviours for those with intellectual and developmental disabilities. Such strategies and methodologies should be flexible and online accessible so that they can be utilised readily by family members, carers, and teachers, in conjunction with those with disabilities.

\section{References}

1. Thoreau E (2006) Ouch!: An Examination of the Self-representation of Disabled People on the Internet. Journal of Computer-Mediated Communication 11(2): 442-468.

2. Molin M, Sorbring E, Lofgren-Martenson L (2017) New Em@ncipatory Landscapes? Young People with Intellectual Disabilities, Internet Use and Identification Processes. Advances in Social Work 18(2): 1-18.

3. Chiner E, Gomez-Puerta M, Cardona-Molto (2017) Internet and People with Intellectual Disability: An Approach to Caregivers' Concerns, Prevention Strategies and Training Needs. Journal of New Approaches in Educational Research 6(2): 154-158.

4. Molin M, Sorbring E, Löfgren-Martenson L (2015) Teachers' and Parents' Views on Internet and Social Media Usage by Pupils with Intellectual Disabilities. JOID 19(1): 22-23.

5. Gilmore L, Cuskelly M (2014) Vulnerability to Loneliness in People with Intellectual Disability: An Explanatory Model. Journal of Policy and Practice in Intellectual Disabilities 11(3): 192-199.

6. Chadwick DD, Wesson (2006) Internet Access by People with Intellectual Disabilities: Inequalities and Opportunities. Future Internet 5: 376-397.

7. Shpigelman CN (2018) Leveraging Social Capital of Individuals with Intellectual Disabilities Through Participation on Facebook. J Appl Res Intellect Disabil 31(1): 79-91.

8. Caton S, Chapman M (2016) The Use of Social Media and People with Intellectual Disability: A Systemic Review and Thematic Analysis. Journal of Intellectual and Developmental Disability 41: 125-139.

9. Wells M, Mitchell KJ (2014) Patterns of Internet Use and Risk on Online Victimization for Youth with and Without Disabilities. Journal of Special Education 4(3): 204-213.

10. Chadwick D, Quinn S, Fullwood C (2016) Perceptions of the Risks and Benefits of Internet Access and Use by People with Intellectual Disabilities. Learn Disabil. 45(1): 21-31.

11. Werner S, Shpigelman CN (2019) Information and Communication Technologies: where are Persons with Intellectual Disabilities? Israel Journal of Health Policy Research 8(6): 1-3. 
12. Luckasson R, Bornthwick Duffy S, Buntoix W, et al (2002) Mental Retardation: Definition, Classification and Systems as Supports. American Association on Mental Retardation Washington DC.

13. Salmerón L, Gómez, M, Fajardo I (2016) How students with intellectual disabilities evaluate recommendations from internet forums. Reading and Writing 29(8): 1653-1675.

14. Buijs PCM, Boot E, Shugar A, Fung WLA, Anne S Bassett (2016) Internet Safety Issues for Adolescents and Adults with Intellectual Disabilities. Journal of Applied Research in Intellectual Disabilities 30(2): 416-418.

15. Boonaert T, Vettenbur N (2011) Young people's Internet use: Divided or diversified. Childhood: A Global Journal of Child Research 18(1): 5466.

16. Freckelton I (2013) Autism Spectrum Disorder: Forensic Issues and Challenges for Mental Health Professionals and Courts. Journal of Applied Research in Intellectual Disabilities 26(5): 420-434.

17. Freckelton I (2011) Asperger's Disorder and the Criminal Law. J Law Med 18(4): 677-694.

18. Freckelton I (2020) Attention Deficit Hyperactivity Disorder (ADHD) and the Criminal Law. Psychiatry, Psychology and Law 26(6): 817-840.

19. Freckelton I (2019) Tourette's Disorder and the Criminal Law. Journal of Law and Medicine 27: 223-238.

20. Freckelton I (2020) Obsessive Compulsive Disorder and the Criminal Law. Psychiatry, Psychology and Law (in press)

21. Douglas H (2015) 'Foetal Alcohol Spectrum Disorders: A Consideration of Sentencing and Unreliable Confession. J Law Med 23: 427-442.

22. Freckelton I (2016) Expert Evidence in Fetal Alcohol Spectrum Disorder Cases. Ethics, Medicine and Public Health 2: 59-75.

23. Freckelton I (2016) Assessment and Evaluation of Fetal Alcohol Spectrum Disorder (FASD) and its Potential Relevance for Sentencing: A Clarion Call from Western Australia. Psychiatry, Psychology and Law 24(4): 485-495.

24. Freckelton I (2016) Fetal Alcohol Spectrum Disorders, Expert Evidence and the Unreliability of Admissions During Police Interviews. Psychiatry, Psychology and Law 23(2): 173-183.

25. Freckelton I (2016) Sentencing Offenders with Foetal Alcohol Spectrum Disorder (FASD): The Case for Effective Management. Psychiatry, Psychology and Law 23(6): 815-825.

26. Gary McKinnon Extradition to US Blocked by Theresa May (6 October 2012) BBC News.

27. Love v Government of the United States (2018) 1 WLR 2889.

28. Freckelton I (2020) Autism Spectrum Disorder and Suitability for Extradition. Psychiatry, Psychology and Law 27 (in press).
29. Parkin S [2017] Keyboard Warrior: The British Hacker Fighting for His Life. The Guardian.

30. Glover v Police [2009] NZHC 1150.

31. Excell v New Zealand Police, unreported High Court of New Zealand, Palmerston Registry, 17 February 2010.

32. $R v$ Walker [2008] NZHC 1114.

33. $R$ v Pora [2015] UKPC 9.

34. $R$ v Friend [2004] EWCA Crim 2661.

35. $R$ v Balogh [2015] WLR 3201, (2015) EWCA Crim 44

36. Vlot van Anrooj K, Naaldenberg J, Hilgenkamp TIM, L Vaandrager, K van der Velden, et al. (2019) Towards Healthy Settings for People with Intellectual Disabilities. Health Promotion International daz 054.

37. Ågren KA, Kjellberg A, Hemmingsson H (2018) Access to and Use of the Internet Among Adolescents and Young Adults with Intellectual Disabilities in Everyday Settings. Journal of intellectual and developmental disability 45(1):89-98.

38. Chadwick D, Wesson C (2016) Digital Inclusion and Disability. In: Attrill A, Fullwood C (Eds.), Applied Cyberpsychology Palgrave Macmillan, London.

39. Löfgren Mårtenson L (2008) Love in cyberspace: Swedish young people with intellectual disabilities and the Internet. Scandinavian Journal of Disability Research 10: 125-138.

40. Seale J, Chadwick D (2017) How Does Risk Mediate the Ability of Adolescents and Adults with Intellectual and Developmental Disabilities to Live a Normal Life by Using the Internet? Cyberpsychology: Journal of Pyschosocial Research on Cyberspace 11(1).

41. Chiner E, Gomez Puera M, Cardona Molto MC (2017) Internet and People with Intellectual Disability: An Approach to Caregivers' Concerns, Prevention Strategies and Training Needs. Journal of New approaches in Educational Research 6(2): 153-158.

42. Seale J (2014) The Role of Supporters in Facilitating the use of technologies by Adolescents and Adults with Learning Disabilities: A Place for Positive Risk-taking. European Journal of Special Needs Education 29(2): 220-236.

43. Chadwick D, Wesson C, Fullwood C (2013) Internet Access by People with Intellectual disabilities: Inequalities and Opportunities. Future Internet 5(3): 376-397.

44. Australian Human Rights Commission (2013) Human Rights and the Internet.

45. Chadwick D, Quinn S, Fullwood C (2017) Perceptions of the Risks and Benefits of Internet Access and Use by People with Intellectual Disabilities. British Journal of Learning Disabilities 45(1): 21-31.

This work is licensed under Creative Commons Attribution 4.0 License DOI: 10.19080/GJIDD.2020.06.555695

\section{Your next submission with Juniper Publishers will reach you the below assets}

- Quality Editorial service

- Swift Peer Review

- Reprints availability

- E-prints Service

- Manuscript Podcast for convenient understanding

- Global attainment for your research

- Manuscript accessibility in different formats

( Pdf, E-pub, Full Text, Audio)

- Unceasing customer service

Track the below URL for one-step submission https://juniperpublishers.com/online-submission.php 